\title{
Online Detecting Method for Transformer Winding Deformation Based on Current Extraction
}

\author{
ZHANG Ning, ZHANG Meng, ZHANG Yuan-yuan \& ZHU Yong-li
}

School of Electrical and Electronic Engineering, North China Electric Power University, China

Keywords: Transformer winding deformation, Online detection, Higher harmonic, FRA.

\begin{abstract}
Transformer winding deformation is common in transformer faults. Offline monitoring is mostly used in diagnosis of winding deformation, which has some limitations. So an online detecting method based on extraction of current is proposed. The method increases the higher harmonic of the current that flows into the input end of transformer appropriately. This higher harmonic is regarded as sweep frequency source. Current flowing into the input and outlet end of transformer is measured. And high frequency components are extracted to structure response curves. Transformer winding deformation is diagnosed through the analysis of response curves. The simulation results showed that winding deformation can be reflected effectively in this method.
\end{abstract}

\section{Introduction}

Transformer is one of the important equipment in power system, which has great significance to the safe and reliable operation of power system [1, 2]. Transformer winding deformation is one of the main types of transformer faults because the anti-short circuit ability is poor [3]. Thus, it is necessary to detect transformer winding deformation in a timely and effective manner.

Frequency response analysis (FRA) [4] is a widespread method to detect transformer winding deformation. FRA has high sensitivity in actual measurement, and can detect the transformer without windlass cover, which is easy to operate. But it is an offline detection method. State of the transformer that is offline is inconsistent with the transformer in operation, which affects the measurement and judgment. In contrast, online monitoring method diagnoses transformer when it is in the running state. Compared with the offline testing, it can find winding fault in time and improve authenticity and sensitivity of the diagnosis. Online monitoring method can accumulate a large amount of data. Current data and historical data of transformer winding are put into comprehensive analysis to reduce the error on regular inspection [5]. Literature [6] introduced an online diagnosis method based on the short-circuit reactance method. Voltage and current signals in the primary and secondary side were measured to calculate equivalent Short-circuit reactance of the transformer. The results of the calculation were compared with short circuit reactance of the nameplate to diagnose deformation degree of transformer winding, which ignored the influence of the field test environment on the test data. Literature [7] introduced a set of winding online monitoring system based on pulse injection. The test signal was injected through capacitive voltage divider which was installed on the main feeder of the transformer. The signal may affect the normal operation of transformer, and it may cause interference to other devices.

In view of the above analysis, an online detecting method based on current extraction method is proposed in this paper. And simulation was conducted to prove the correctness and feasibility of this method.

\section{Principle of FRA}

The transformer winding is equivalent to a passive linear network which consists of distributed inductance and capacitance when it is in the high frequency signal excitation, because the core permeability and air permeability are almost the same in this case [8-11]. Frequency response characteristic is the outstanding properties of this system. The frequency response characteristics are exclusive for a certain network. When the transformer winding deformation occurs, parameters of the 
winding equivalent network will change, and the frequency response curves will also alter reflecting at the frequency response characteristics of winding. Winding deformation is distinguished by comparing the difference of frequency response curves based on FRA [12]. A sinusoidal voltage sweep signal is exerted at the side of the transformer winding. And the response signal is measured at the other side of the winding. Then the frequency response curve is drawn out by processing the data. When using FRA, the expression of the winding transfer function is shown in Eq. 1.

$$
H(\omega)=20 \log \frac{U_{o}(\omega)}{U_{i}(\omega)} .
$$

Where, $U_{\mathrm{i}}(\omega)$ is the amplitude of the input frequency sweep voltage signal. $U_{\mathrm{o}}(\omega)$ is the amplitude of the output frequency sweep voltage signal.

\section{Principle of current extraction method}

With the development of power electronic technology and microelectronics technology, a large number of nonlinear devices are used in power system, which causes serious harmonic pollution to power system. Non-sinusoidal current signal with $2 \pi / \omega$ for cycle generally meets the Dirichlet condition, and can be decomposed into fundamental wave and a series of different frequency harmonic using Fourier series, as shown in Eq. 2. Where, the harmonic order is the ratio of integers about harmonic frequency and fundamental frequency.

$$
\mathrm{i}(\omega t)=a_{0}+\sum_{n=1}^{\infty} c_{n} \sin \left(\mathrm{n} \omega \mathrm{t}+\phi_{\mathrm{n}}\right) .
$$

The relations among each value are shown from Eq. 3 to Eq. 6.

$$
\begin{aligned}
& c_{n}=\sqrt{a_{n}^{2}+b_{n}^{2}} . \\
& \phi_{\mathrm{n}}=\arctan \left(\frac{a_{n}}{b_{n}}\right) . \\
& a_{\mathrm{n}}=c_{n} \sin \phi_{n} . \\
& b_{\mathrm{n}}=c_{n} \cos \phi_{n} .
\end{aligned}
$$

The content of n-th harmonic current component is usually shown by the containing rate of n-th harmonic $H R I_{n}$, which is the percent of effective value between harmonic current and fundamental current, as shown in Eq. 7.

$$
H R I_{\mathrm{n}}=\frac{I_{n}}{I_{1}} \times 100 \% \text {. }
$$

Actually the higher harmonic content is too low to be detected, which reduces the accuracy of FRA. Current extraction method is proposed to improve the problem in this paper. Nonlinear components are installed in the input end of the transformer to appropriately raise the higher harmonic content of the current that flows into the transformer. The higher harmonic is regarded as sweep frequency source. The current is measured at the input and outlet end of transformer. The high frequency components of the current are extracted through signal processing methods. The FRA expression is $H(\omega)=20 \lg \left(I_{0}(\omega) / I_{\mathrm{i}}(\omega)\right)$. Finally the frequency response curves are structured to analyze and diagnose transformer winding deformation.

\section{Simulated analysis}

\subsection{Establishment of simulation model}

Matlab was used to establish simulation model, which has 6 levels, as shown in Figure 1. Sinusoidal current frequency sweep signal was added on one side of the winding to simulate the high-frequency current signal which flows into the input end of the transformer after the adjustment 
by relevant nonlinear components. Order of magnitude sweep was set as the sweep frequency mode. The range of scanning is from $1 \mathrm{kHz}$ to $1 \mathrm{MHz}$. And the scanning point is 200 in each order of magnitude.

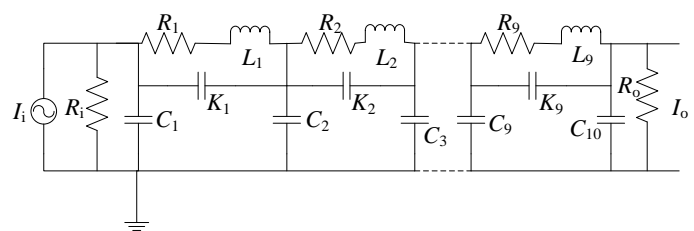

Figure 1: Equivalent model of transformer winding.

Where, $\mathrm{L}$ is the winding inductance. $\mathrm{C}$ is the winding ground capacitance. $\mathrm{K}$ is the winding longitudinal capacitance. $R_{\mathrm{i}}$ is the input matching resistor. $R_{\mathrm{o}}$ is equivalent resistance of output measurement loop. $R_{1} \sim R_{9}$ are equivalent resistances standing for the winding loss, which are represented by $R$ in Table 1 . There is important influence on the frequency response characteristics of transformer winding to take the winding loss into consideration. In this simulation, the distribution parameters of the transformer winding are assumed as uniform distribution parameters, as shown in Table 1.

\begin{tabular}{ccccccc}
\hline $\begin{array}{c}\text { Paramet } \\
\text { er }\end{array}$ & $\begin{array}{c}L_{\mathrm{i}} /[\mathrm{m} \\
\mathrm{H}]\end{array}$ & $\begin{array}{c}K_{\mathrm{i}} /[\mathrm{p} \\
\mathrm{F}]\end{array}$ & $C_{\mathrm{i}} /[\mathrm{pF}]$ & $R /[\Omega$ & $R_{\mathrm{i}} /[\Omega]$ & $R_{\mathrm{o}} /[\Omega$ \\
] & & ] & ] \\
\hline Value & 40.426 & 19.5 & 1213.27 & 1 & 1 & 5 \\
\hline
\end{tabular}

Table 1: Simulation parameters.

\subsection{Simulation with current extraction method}

$\mathrm{L}, \mathrm{K}$ and $\mathrm{C}$ of the model will change when winding deformation happens, which causes the position of the peaks and troughs in the frequency response curve change. Different parameters are changed to simulate transformer winding deformation in this simulation. The frequency response curves that are measured before and after the winding deformation are compared to diagnose the winding deformation and prove the correctness of this online monitoring method.

\subsubsection{Different types of deformation}

Take the parameters change in level 5 for example. L, K and C in level 5 are increased by 20\% successively, and the frequency response curves are shown in Figure 2. Dotted line represents the winding under normal conditions, and solid line represents the winding after changing parameters. Curves behind are similar to this expression format.

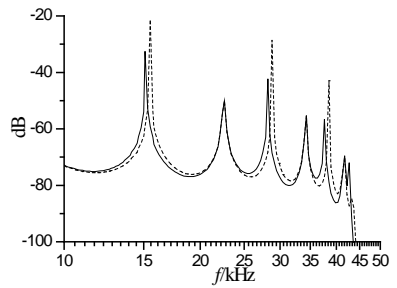

(a) Increase $L_{5}$ for $20 \%$

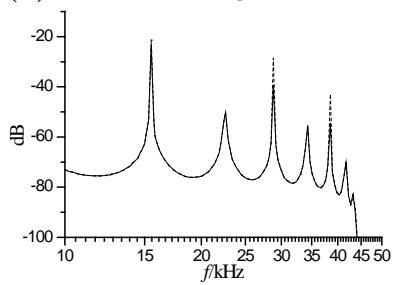

(b) Increase $K_{5}$ for $20 \%$ 


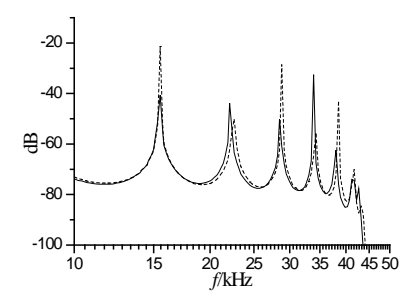

(c) Increase $C_{5}$ for $20 \%$

Figure 2: Simulation results after increasing $L_{5}, K_{5}$ and $C_{5}$ by $20 \%$ successively.

Contrast of frequency response curves is shown in Table 2. It is obvious that the curves are sensitive to the change of $\mathrm{L}$ and $\mathrm{C}$, but they are insensitive to $\mathrm{K}$. Rough types of winding deformation can be confirmed according to the characteristics of the frequency response curves.

\begin{tabular}{|c|c|c|}
\hline & Offset of peaks & $\begin{array}{l}\text { Amplitude change of } \\
\text { peaks }\end{array}$ \\
\hline $\begin{array}{l}\text { Increase } \\
L_{5} \text { for } \\
20 \%\end{array}$ & $\begin{array}{l}\text { Peaks of } 1,3 \text { and } 5 \text { shift } \\
\text { to the left obviously, but } \\
\text { peaks of } 2 \text { and } 4 \text { do not } \\
\text { move. }\end{array}$ & $\begin{array}{l}\text { Peaks of } 1,3 \text { and } 5 \\
\text { decrease, but peaks of } 2 \\
\text { and } 4 \text { do not change. }\end{array}$ \\
\hline $\begin{array}{l}\text { Increase } \\
K_{5} \text { for } \\
20 \%\end{array}$ & $\begin{array}{l}\text { There is no offset in all } \\
\text { peaks. }\end{array}$ & $\begin{array}{l}\text { Peaks of } 3 \text { and } 5 \\
\text { decrease. }\end{array}$ \\
\hline $\begin{array}{l}\text { Increase } \\
C_{5} \text { for } \\
20 \%\end{array}$ & $\begin{array}{l}\text { Peaks of } 2,3,4 \text { and } 5 \\
\text { shift to the left. }\end{array}$ & $\begin{array}{l}\text { Peaks of } 1,3,5 \text { and } 6 \\
\text { decrease, but peaks of } \\
2,4 \text { and } 7 \text { increase }\end{array}$ \\
\hline
\end{tabular}

Table 2: Contrast of frequency response curves after increasing $L_{5}, K_{5}$ and $C_{5}$ by $20 \%$ successively.

\subsubsection{Different degree of deformation}

Take the parameters change in level 5 for example. L, K and C in level 5 are increased by 10\%, $20 \%$ and $30 \%$ successively. Simulation results showed that different degree of deformation can be diagnosed effectively by comparing the difference among the curves. The change of $L$ is illustrated which is shown in Figure 3 and there are no unnecessary details about the rest of the frequency response curves about $\mathrm{K}$ and $\mathrm{C}$.

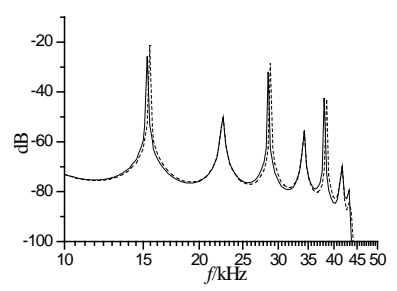

(a) Increase $L_{5}$ for $10 \%$

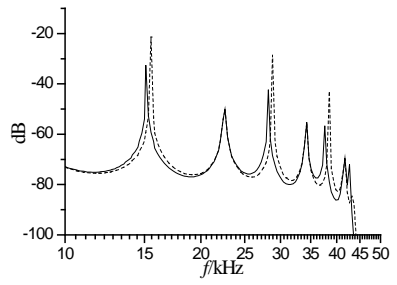

(b) Increase $L_{5}$ for $20 \%$

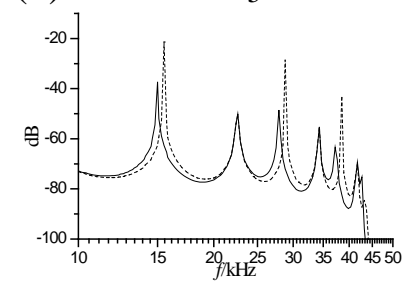


(c) Increase $L_{5}$ for $30 \%$

Figure 3: Simulation results after increasing $L_{5}$ by different proportion.

Figure 3 shows that with the increase of $L_{5}$, the degree of peaks 1,3 and 5 that shift to the left is increasing. And the decrease extent of these three peaks is also on the rise. Therefore the degree of deformation can be diagnosed by analyzing frequency response curves.

\subsubsection{Different location of deformation}

L, K and C are increased by 20\% at level 1, 3, 5, 7 and 9 successively. Results showed that winding deformation at different locations can be diagnosed effectively by comparing the differences among the curves. The change of $\mathrm{L}$ is illustrated which is shown in Figure 4 and there are no unnecessary details about the rest of the frequency response curves about $\mathrm{K}$ and $\mathrm{C}$. The results showed that the change of the frequency response curves is central symmetry about level 5, that is curves of level 1 is the same as level 7, so is level 3 and level 9. So the repetitive curves of level 7and 9 are not shown. Contrast of frequency response curves in Figure 4 is shown in Table 3.

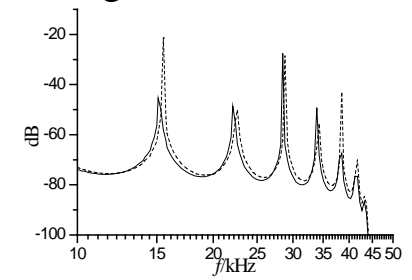

(a) Increase $L_{1}$ for $20 \%$

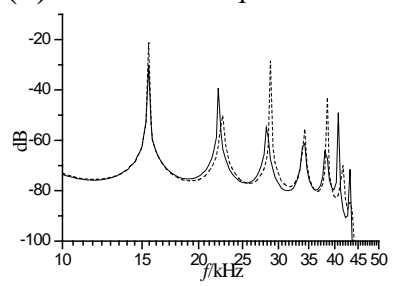

(b) Increase $L_{3}$ for $20 \%$

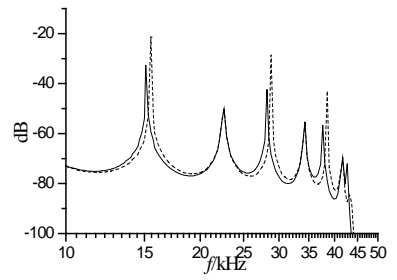

(c) Increase $L_{5}$ for $20 \%$

Figure 4: Simulation results after increasing $L$ by $20 \%$ in different positions.

\begin{tabular}{|c|c|c|}
\hline & Offset of peaks & $\begin{array}{l}\text { Amplitude change of } \\
\text { peaks }\end{array}$ \\
\hline $\begin{array}{c}\text { Increase } L_{1} \text { for } \\
20 \%\end{array}$ & $\begin{array}{l}\text { Peaks of } 1,2,3 \\
\text { and } 4 \text { shift to } \\
\text { the left. }\end{array}$ & $\begin{array}{l}\text { Peaks of } 1,5 \text { and } 6 \\
\text { decrease, but others do } \\
\text { not change. }\end{array}$ \\
\hline $\begin{array}{c}\text { Increase } L_{3} \text { for } \\
20 \%\end{array}$ & $\begin{array}{l}\text { Peaks of } 2,3 \\
\text { and } 6 \text { shift to } \\
\text { the left. }\end{array}$ & $\begin{array}{l}\text { Peaks of } 1,3,4 \text { and } 5 \\
\text { decrease, but peaks of } 2 \text {, } \\
6 \text { and } 7 \text { increase. }\end{array}$ \\
\hline $\begin{array}{c}\text { Increase } L_{5} \text { for } \\
20 \%\end{array}$ & $\begin{array}{l}\text { Peaks of } 1,3 \\
\text { and } 5 \text { shift to } \\
\text { the left. }\end{array}$ & $\begin{array}{l}\text { Peaks of } 1,3 \text { and } 5 \\
\text { decrease, but others do } \\
\text { not change. }\end{array}$ \\
\hline
\end{tabular}

Table 3: Contrast of frequency response curves after increasing L by $20 \%$ in different positions.

\section{Conclusions}

(1) In view of the problems about offline detection, an online detecting method based on current 
extraction method is proposed in this paper. Nonlinear components are installed at the input end of the transformer to appropriately raise the higher harmonic content of the current that flows into the transformer. And the higher harmonic is regarded as sweep frequency source. Measure the current at the input and outlet end of transformer and extract the high frequency components of the current. Finally structure the frequency response curves to analyze and diagnose transformer winding deformation. The simulation results of different fault condition showed that this method can diagnose winding deformation effectively.

(2) In this method, the extraction and screening of high frequency component from the measured current data need further researches.

\section{References}

[1] Liu, X. P. \& Chen, M. Y., A Novel Method on On-line Monitoring of Winding Deformation of Transformers. Power System Protection and Control, 41(12), pp. 20-26, 2013.

[2] Arri, E., Carta, A., Moeei, F. \& Tosi, M., Diagnosis of the Power Transformer Winding Via On-line Stray Inductance Measurement. IEEE trans. on Instrum. Meas, 42(2), pp. 372-378, 1993.

[3] Arri, E. \& Moeei, F., Status Assessment of Transformer Wingdings Via On-line Stray Inductance Measurement. IEEE Instrum. Meas. Technology, pp. 1171-1174, 1994.

[4] DL/T911-2004, Frequency Response Method of Power Transformer Winding Deformation.

[5] Wang, Z. J., Xu, Y. F. \& Liu, S. M., Condition Monitoring and Fault Diagnosis of Power Equipment. Shanghai: ShangHai Jiao Tong University Press, pp. 2-3, 2012.

[6] He, W., Liu, Y. G. \& Hu, G. H., On-line Diagnosis of the Distribution Transformer Winding Deformation Based on the Short-Circuit Reactance Method. Electrical Measurement \& Instrumentation, 51(14), pp. 47-51, 2014.

[7] Liu, Y. Q., Chen, T. \& Dong, Y., Research on the On-line Monitoring System for Winding Deformation of Distribution Transformers Based on Pulse Injection. Electric Power Science and Engineering, 30(4), pp. 24-27, 2014.

[8] Vaessen, P. T. \& Hanique, E., A New Frequency Response Analysis Method for Power Transformers. IEEE Trans. on Power Delivery, 7(1), pp. 384-391, 1992.

[9] Li, D. S., Lei, M. \& Chen, J., Research on Digital Signal Processing Algorithm of Transformer Distortion Tester. Electrical Measurement \& Instrumentation, 42 (11), pp. 9-11, 2005.

[10] Liu, H. L. \& Lei, X., A Detecting System for Transformer Winding Slight Deformation Based on Impulse Response Analysis. Electrical Measurement \& Instrumentation, 48(11), pp. 10-13, 2011.

[11] Islam, S. M., Detection of Shorted Turns and Winding Movements in Large Power Transformers Using Frequency Response Analysis. 2000 IEEE Power Engineering Society Winter Meeting, pp. 2233-2238, 2000.

[12] Liu, L. P., Qiao, Y. L., Zhu, Y. L. \& Wang, G. Q., The Monitoring and Diagnosis for Transformer Winding Deformation Based on Current Source Method. Electrical Measurement \& Instrumentation, 51(8), pp. 56-59, 2014. 